\title{
Tolerability and Treatment Effects of Pelargonium sidoides Preparation EPs 7630 in Adults Suffering from Acute Rhinopharyngitis - A Prospective, Open-Label Trial
}

\section{Keck $\mathrm{T}^{1^{*}}$, Strobl $\mathrm{A}^{2}$ and Stracke $\mathrm{B}^{3}$}

${ }^{1}$ Department of ENT Medicine, Head and Neck Surgery, Krankenhaus, Elisabethinen GmbH Graz, Austria

${ }^{2}$ Department of ENT Medicine, Head and Neck Surgery, Krankenhaus der Barmherzigen Schwestern Linz Betriebsgesellschaft m.b.H, Linz, Austria ${ }^{3}$ Department of Clinical Research, Dr. Willmar Schwabe GmbH \& Co. KG, Karlsruhe, Germany

\begin{abstract}
Background: EPs 7630 has already been proven effective in acute rhinopharyngitis (ARP) and other acute respiratory diseases. We conducted an open-label, non-comparative, interventional multicenter study to obtain additional information on the tolerability and effectiveness of EPs 7630 in a clinical practice setting.

Methods: 120 adults with clinical ARP diagnosis and at least 2 out of a set of 10 common cold symptoms received $3 \times 1$ film-coated $20 \mathrm{mg}$ EPs 7630 tablet daily, for 10 days. Assessment of tolerability and safety was based on adverse event (AE) elicitation and safety laboratory measures. The intensity of ARP-associated symptoms was assessed daily and treatment outcome and satisfaction were evaluated.

Results: At treatment end, $42 \%$ of patients were completely recovered, $42 \%$ showed major improvements. The majority of patients were satisfied with treatment. Over-all AE incidences were 0.017 (all AEs) and 0.010 (potentially related AEs) events/day of exposure. Most common events were gastrointestinal complaints and skin reactions. None of the events were serious.

Conclusions: The results confirm the excellent tolerability of EPs 7630 . Potentially attributable AEs were limited to the drug's known spectrum of adverse effects. The majority of patients showed a favorable course of ARP which is unlikely to be explained by the natural course of the disease alone.
\end{abstract}

Keywords: Pelargonium sidoides; Common cold; Clinical trial; Tolerability; Bacterial and viral analysis; Treatment for the common cold

\section{Introduction}

The common cold or acute rhinopharyngitis (ARP), respectively, is characterized by nasal stuffiness and discharge, sneezing, sore throat, and cough. Symptoms peak 2-3 days after the onset of infection, with some symptoms, e.g. coughs and general discomfort, persisting for up to 3 weeks [1]. On average, adults suffer from 2-3 episodes of ARP per year, leading to time off work [2]. Consequently the economic burden resulting from lost productivity and expenditures for treatment is enormous $[3,4]$.

It is estimated that at least $90 \%$ of ARP infections are caused by viruses [5-7] such as rhinovirus, corona virus, and respiratory syncytial virus (RSV) [8]. The pathogenesis of ARP involves a complex interplay between replicating viruses and inflammatory response of the host. Viral infection of the nasal mucosa results in vasodilatation and increased vascular permeability, which in turn cause nasal obstruction and rhinorrhea. Cholinergic stimulation leads to increased mucous gland secretion and sneezing [9]. The mechanism by which the viral infection of the common cold engenders cough is unclear [10]. However, an association among cough, throat clearing, and postnasal drip has been demonstrated [11]. Moreover, due to the inflammation of the nasal mucosa, the ostia of the paranasal sinuses and the Eustachian tubes may become obstructed, abetting the development of secondary inflammation such as sinusitis or otitis media [12].

Transmission of ARP is mostly achieved through hand-to-hand contact, with subsequent passage to the nostrils or eyes [13]. Current treatment strategies for ARP aim at relieving symptoms, shortening the illness, and reducing complications as well as the infectivity to others
[2]. Due to the predominantly viral etiology of ARP, treatment with antibiotics, that is still quite common in clinical practice, is inappropriate and can be even harmful. As antibiotic treatment has the potential of causing adverse reactions and increasing antibiotic resistance [2], treatment options that are efficacious in reducing the symptom burden of the patient and accelerating remission without causing bothersome adverse effects have gained interest during recent years.

EPs $7630^{1}$ is a herbal drug preparation from the roots of Pelargonium sidoides, a medicinal plant grown in South Africa. The product is available in both tablet and liquid forms for the treatment of acute respiratory tract infections, such as ARP or acute bronchitis. It is marketed in several countries in Asia, Europe, Australia, as well as Central and South America.

Pharmacological activities of EPs 7630 and several of its isolated constituents have been demonstrated in in-vitro studies. They include

${ }^{1} \mathrm{EPs} \otimes 7630$ is the active ingredient of the product Umckaloabo® (ISO Arzneimittel, Ettlingen, Germany)

*Corresponding author: Tilman Keck, Krankenhaus der Elisabethinen Graz $\mathrm{GmbH}$, Elisabethinergasse 14, 8020 Graz, Austria, Tel: 4331670631140; Fax : 4331670631620,E-mail: Tilman.Keck@elisabethinen.at

Received October 12, 2015,; Accepted October 30, 2015, ; Published November 06, 2015

Citation: Keck T, Strobl A, Stracke B (2015) Tolerability and Treatment Effects of Pelargonium sidoides Preparation EPs 7630 in Adults Suffering from Acute Rhinopharyngitis - A Prospective, Open-Label Trial. Altern Integ Med 4: 204 doi:10.4172/2327-5162.1000204

Copyright: (C) 2015 Keck T, et al. This is an open-access article distributed unde the terms of the Creative Commons Attribution License, which permits unrestricted use, distribution, and reproduction in any medium, provided the original author and source are credited. 
a moderate direct antibacterial and antiviral action as well as notable immune-modulatory capabilities [14]. The latter are mediated mainly by the release of tumor necrosis factor $\alpha$ and nitric oxides, the stimulation of interferon- $\beta$, and an increase in natural killer cell activity [15-18]. Biological activities include an improved phagocytosis, oxidative burst and intracellular killing by human peripheral blood phagocytes, as well as an inhibition of the interaction between group-A streptococci and host epithelia [19,20] and increased stress resistance [21]. A potent HIV 1 attachment inhibition by EPs 7630 has been shown by Helfer et al. [22]. Moreover, EPs 7630 was shown to interfere with the replication of seasonal influenza A virus strains $(\mathrm{H} 1 \mathrm{~N} 1, \mathrm{H} 3 \mathrm{~N} 2)$, respiratory syncytial virus, human coronavirus, parainfluenza virus, and coxsackie virus [23]. Anti-influenza virus activity of the herbal extract was also confirmed in an animal model [24].

The efficacy of EPs 7630 in the treatment of acute respiratory tract infections has been investigated in several controlled clinical trials, the majority of which have been performed in the indication of acute bronchitis, while studies are also available for acute rhinosinusitis, acute tonsillopharyngitis, and in ARP. For these conditions, systematic reviews indicate significant advantages of EPs 7630 over placebo [2528].The existing information regarding the tolerability and safety of EPs 7630 has been derived mainly from randomized, controlled trials whose primary objective was to investigate the efficacy of the extract, as well as from post-marketing surveillance studies [29]. Clinical trials provide a high degree of control of the experimental setting and are performed in patient populations appropriate for meeting the primary objectives of the study. Post-marketing surveillance projects, on the other hand, are non-interventional by nature and are thus subject to limitations with respect to a standardized treatment or visit schedule, etc. An interventional post-marketing trial in the registered indication may thus provide valuable safety and effectiveness information in a clinical real-life setting which we consider to be important for physicians and their patients [30]. We present the results of an openlabel, non-comparative, phase IV clinical trial designed to obtain further information on the tolerability and effectiveness of EPs 7630 in a clinical practice setting, as well as to gain further insight into the bacterial and viral flora in patients suffering from the common cold. In accordance with the design, this study was not intended for demonstrating treatment efficacy, but to investigate the performance of the drug in a 'real-life' situation, yet under the well-defined conditions of an interventional trial.

\section{Materials and Methods}

\section{Protocol and design, objectives}

We present the results of an open-label, non-comparative, interventional multicenter study performed with EPs 7630 in patients suffering from symptoms of ARP.

After enrolment, eligible patients underwent 10 days of treatment with EPs 7630. Examinations were scheduled at baseline and treatment end, with an interim visit to be performed after 5 days of treatment. Moreover, the participants were asked to maintain a diary of their disease-related symptoms on a daily basis.

The protocol was reviewed and approved by an independent ethics committee. All patients provided written informed consent. The principles of Good Clinical Practice and the Declaration of Helsinki were adhered to.

\section{Participants}

The study participants were female and male out-patients with a clinical diagnosis of ARP and at least 2 out of 10 pre-defined common cold symptoms (CCS; nasal discharge, sore throat, nasal congestion, sneezing, scratchy throat, hoarseness, coughing, headache, malaise, fever). Main specific criteria for exclusion were obstructive anatomic lesions in the nasopharynx (e.g., nasal polyps), severe septal deviations, previous or planned surgery of the nose or paranasal sinuses, chronic pulmonary diseases, allergic rhinitis, conditions known to cause sore throat (e.g., tonsillo-pharyngitis, drugs, aphthous ulcers, candida), or the presence of any acute respiratory tract disease other than ARP. Concomitant intake of common cold medications that might impair the interpretation of trial results were not allowed during study participation. However, in the event of fever $>38.5^{\circ} \mathrm{C}$ the participants were allowed to take paracetamol up to a maximum dose of $500 \mathrm{mg}$ taken every 6 hours.

\section{Intervention}

EPs 7630 is a herbal preparation from the roots of Pelargonium sidoides (1:8-10), extraction solvent: ethanol 11\% (w/w). Film-coated tablets containing $20 \mathrm{mg}$ of EPs 7630 were used ${ }^{\$}$. The study participants had to administer $3 \times 1$ film-coated tablets daily for 10 consecutive days (total daily dose: $60 \mathrm{mg}$ EPs 7630 ). The investigational product was provided by the manufacturer (Dr. Willmar Schwabe GmbH \& Co. KG, Karlsruhe, Germany).

\section{Outcomes}

Upon study inclusion information regarding the study participants' demographic, anthropometric and patient history data was obtained. Documented measures included sex, age, ethnic group, smoking habit and alcohol consumption, height, weight, duration of ARP symptoms, as well as previous and concomitant diseases and medication.

Tolerability was assessed by questioning patients for adverse events (AEs) of any kind during all post-baseline visits. Moreover, safety laboratory assessments, which included erythrocyte sedimentation rate (ESR), erythrocytes, thrombocytes, leucocytes, serum creatinine, alkaline phosphatase (ALP), gamma-glutamyl-transpeptidase ( $\gamma$-GT), aspartate aminotransferase (AST), alanine aminotransferase (ALT), total bilirubin, albumin, prothrombin time (PT), partial thromboplastin time (PTT), and C-reactive protein (CRP), as well as general clinical and physical examinations were performed at baseline and at the end of treatment.

Outcome measures referring to treatment effectiveness and to the course of ARP during the period of observation included investigator ratings of each of a set of 10 common cold symptoms (CCS) on a 4-point verbal rating scale ranging from 0 ('not present') to 3 ('severe') which were assessed during each visit and summed up to a total score. The CCS is based on a score developed by Jackson et al. [31-33].

Observer assessments also included 8 additional ARP-associated complaints (pulmonary rales at auscultation, sputum production, chest pain during coughing, chilliness, exhaustion, loss of appetite, diarrhea, and muscle aches) which the investigators rated using the same scale and which were summed up to a separate total score. Specific guidance for the grading of each of the symptoms was given in the study protocol. Daily self-ratings for a set of 15 ARP-associated symptoms (runny nose, congested nose, sneezing, sore throat, scratchy throat, hoarseness,

$\S$ Marketed product used in this trial: Kaloba® (Austroplant Arzneimittel, Vienna, Austria) 
coughing, headache, malaise, chilliness, chest pain during coughing, loss of appetite, restless sleep, limitation of usual daily activities, muscle ache) were obtained by means of a 5-point verbal rating scale ranging from 0 ('not at all') to 4 ('severe') in the patient diary. The same scale was also used for obtaining a daily self-rating of how ill the patient felt.

The over-all recovery from ARP (rated by patients and investigators) as well as the patients' satisfaction with the treatment outcome were assessed using the Integrative Medicine Outcomes Scale (IMOS) and the Integrative Medicine Patient Satisfaction Scale (IMPSS), respectively [34]. Further effectiveness outcome measures were the number of days off work or education, the need for antibiotic treatment, and the use of paracetamol.

At baseline, a nasopharyngeal swab was taken from both nostrils for microbiological testing by means of a sterile brush. Total nucleic acid (DNA and RNA) was isolated from the samples using the QIAamp nucleic acid isolation kit (Qiagen, Hilden, Germany). The amount of isolated nucleic acid was measured by absorbance. For viral testing, an aliquot was applied to the $\mathrm{xTAG}^{\circledR}$ Respiratory Viral Panel (RVP) FAST assay (Abbott, Vienna, Austria). cDNA were generated from RNA by reverse transcription (RT) and then amplified by PCR. Subsequent to RT-PCR the amplicons were hybridized onto virus species specific DNA probes immobilized on Luminex beads. Virus species were identified using Luminex technology, with signal measurements of virus specific hybridization signals specified for the $\mathrm{XTAG}^{\circ} \mathrm{RVP}$ FAST assay. Viruses detectable by the assay include influenza A and B, respiratory syncytial virus (RSV), corona virus, parainfluenza virus, human metapneumovirus, entero-rhinovirus, adenovirus, and human bocavirus. Testing of bacterial DNA was done using the AIT Chip HD PathoID test (Austrian Institute of Technology).

PCR amplicons were generated from nucleic acid extracts using universal primers targeting bacterial $16 \mathrm{~S}$ rRNA gene. The PCR products were fluorescently labelled and transferred onto a microarray. The microbial panel for oligonucleotide microarray detection, applying 20- to 30-mer probes, is capable of identifying 70 different pathogens relevant for infectious diseases with pathogen occurrence in clinical samples.

Treatment compliance was assessed by counting the number of remaining film-coated tablets at study exit.

\section{Statistical methods, sample size}

All outcome measures were analyzed descriptively using appropriate summary statistics. For change over time, descriptive p-values were determined. 95\% confidence intervals (CIs) were specified for change over time as well as for AE incidence. Safety and tolerability analyses included all patients having administered the investigational treatment at least once (safety analysis set, SAF). For eligibility of the analyses of effectiveness and course of ARP, at least one post-baseline assessment of the analyzed outcome was also required (full analysis set, FAS). An additional per-protocol (PP) analysis included all patients of the FAS who completed the trial without major protocol deviations. Missing data were imputed by carrying forward the last valid observation provided that at least one post-baseline assessment had been performed.

For statistical tests two-sided p-values up to 0.05 were considered to be descriptively significant. One hundred and twenty patients were planned to be treated in this study based on practical considerations. Using confidence interval methods, the sample size assures a probability of at least $90 \%$ that an event with a true incidence rate of $2 \%$ is observed at least once.

\section{Results}

\section{Participants}

Between January 2011 and November 2012, 120 subjects were included and treated in the out-patient clinics of 8 hospitals in Austria. Three subjects $(2.5 \%)$ terminated their participation in the study prematurely due to withdrawal of consent, an adverse event (allergic dermatitis), and known, pre-existing hepatitis which the subject had failed to report upon enrolment.

All patients included were analyzed for safety in the SAF and for effectiveness in the FAS, respectively. One hundred and three patients (85.8\% of 120) were analyzed for effectiveness in the PP analysis data set. Major protocol deviations leading to an exclusion from the PP analysis were premature termination unrelated to (lack of) efficacy or tolerability $(\mathrm{n}=2)$, relevant violations of inclusion or exclusion criteria $(n=2)$, relevant findings in the medical history $(n=1)$, lack of treatment compliance $(\mathrm{n}=2)$, major deviations from the visit schedule $(\mathrm{n}=4)$, using an unsafe method of contraception $(\mathrm{n}=1)$, or use of prior or concomitant medication which was not allowed according to the protocol $(\mathrm{n}=8)$.

Unless otherwise noted, the results presented in the following sections apply to the SAF/FAS.

\section{Baseline characteristics}

The study participants' demographic and anthropometric characteristics are shown in Table 1. Although ethnic group was not a selection criterion, all subjects except 1 were Caucasians (99.2\%). About $2 / 3$ of the subjects reported to drink alcohol occasionally. Sixtyone patients $(50.8 \%)$ had never been smokers, and 41 (34.2\%) were current smokers.

At baseline, 12 patients (10.0\%) reported a duration of ARP symptoms of less than 24 hours, 67 (55.8\%) reported a duration of $24-48$ hours, and 41 (34.2\%) had been suffering for more than 48 hours. The baseline severity of CCS and other ARP-associated symptoms showed no monotonic association with symptom duration upon enrolment.

\section{Treatment compliance}

Treatment compliance was calculated as the percentage of tablets used relative to the prescribed amount. Across the entire period of observation, mean \pm SD compliance was $102.7 \% \pm 6.8 \%$. All patients showed compliance within a pre-defined acceptable range of $75 \%$ $125 \%$. However, 2 patients were treated for fewer than 7 days, which was considered to be a relevant protocol deviation.

\section{Course of ARP, effectiveness}

At baseline, the study participants presented with observer rated CCS total scores between 2 and 21 points (out of a maximum possible score of 30 points) and reported the presence of between 2 and all of the 10 CCS; 106 out of the 120 patients $(88.3 \%)$ presented with at least 5 different symptoms at baseline. Symptom scores indicate a continuing remission of ARP-related symptoms during the course of treatment. The average total score decreased significantly from a baseline mean value of 10.8 points, over 5.1 points at the interim visit scheduled at day 5 , to 2.2 points at treatment end (Table 2), corresponding to decreases by $52.8 \%$ and by $79.6 \%$ of the baseline value at day 5 and treatment end, respectively. A total of 2 patients (1.7\%) were symptom free at day 5 and 28 patients $(23.9 \%)$ were symptom free at day 10 . Likewise, the number of patients with only one symptom remaining was $10(8.6 \%)$ and 31 


\begin{tabular}{|l|l|l|l|}
\hline \multicolumn{2}{|c|}{} & $\begin{array}{l}\text { SAF/FAS } \\
(\mathbf{n = 1 2 0})\end{array}$ & $\begin{array}{l}\text { PPS } \\
(\mathbf{n = 1 0 3 )}\end{array}$ \\
\hline Sex & Female & $84(70.0 \%)$ & $72(69.9 \%)$ \\
\hline & Male & $36(30.0 \%)$ & $31(30.1 \%)$ \\
\hline Age (years) & $38.9 \pm 13.6$ & $39.5 \pm 13.9$ \\
\hline Height $(\mathrm{cm})$ & $171.3 \pm 8.1$ & $171.2 \pm 8.3$ \\
\hline Weight $(\mathrm{kg})$ & $73.1 \pm 14.4$ & $73.2 \pm 14.8$ \\
\hline $\begin{array}{l}\text { Duration of } \\
\text { [hours] }\end{array}$ & ARP symptoms & $46.2 \pm 18.3$ & $44.8 \pm 18.3$ \\
\hline
\end{tabular}

SAF: Safety Analysis Set; FAS: Full Analysis Set; PPS: Per-Protocol Analysis Set

Table 1: Baseline characteristics (number (\%) of patients or mean \pm SD)

(26.7\%) at days 5 and 10, respectively. At day 10, 55 patients out of 117 with valid data $(47.0 \%)$ had a CCS total score $\leq 1$ point and $83(70.9 \%)$ had a score $\leq 2$ points. A similar alleviation of symptoms was observed for the total score of other ARP-associated complaints as well (Table 2). The results in the FAS and in the PP analysis were comparable.

Figure 1 shows the time course of the 14-item summary score for the ARP symptom self-rating obtained in the patients' diary (theoretical maximum: 60 points) together with the percentage of patients who felt only mildly ill or not ill at all. The data indicate a monotonic decrease of symptom intensity. The time course resembled an exponential curve with mean values ranging from $22.1 \pm 9.6$ points at baseline, over 11.4 \pm 9.1 points at day 5 , to $3.8 \pm 4.2$ points at day 10 . At the same time, the percentage of patients who felt only mildly ill or not ill at all increased from $15.3 \%$ at baseline to $58.6 \%$ at day 5 and to $94.6 \%$ at day 1. A total of 37 patients (30.8\% of 120 ) were unable to attend work or school/college for at least 1 day, up to a maximum of 11 days. The average number of days off work or education was $1.7 \pm 3.3$ days (including patients with zero days off). According to the decision of the investigator, 2 subjects (1.7\% of 120 ; $95 \%$ CI: $0.2 \%-5.9 \%)$ required antibiotic treatment, and 22 patients $(18.3 \%)$ took paracetamol at least once. The average intake was $2.5 \pm 2.7$ tablets with a maximum intake of 12 tablets during the 10-day period of observation.

The IMOS rating scale was used for assessing the patients' and investigators' global impression of change in the intensity of ARP in comparison to baseline. Table 3 shows that according to both assessments about $84 \%$ of the patients were either fully recovered or showed major improvements of their condition at treatment end. Unchanged symptoms were reported for 3 and 5 patients according to the investigators' and patients' rating, respectively. Deteriorations were reported for none of the patients. In a subgroup analysis by onset of ARP symptoms relative to inclusion into the trial, 9 out of 12 subjects (75.0\%) whose complaints had started $<24$ hours before inclusion were fully recovered at treatment end, compared to 29 of 66 patients (43.9\%) with an onset $24-48$ hours before inclusion and 11 of 39 subjects $(28.2 \%)$ whose symptoms had started $>48$ hours before inclusion (MantelHaenszel $\chi^{2}$ statistic for the comparison of recovery rates across the three ordered categories for onset: $\mathrm{p}=0.005$ ).

The patients' treatment satisfaction was assessed by means of the IMPSS scale (Table 3). At the final visit, about $3 / 4$ of the study participants indicated that they were satisfied or very much satisfied with the treatment received, whereas 2 patients $(2.0 \%$ of 101 with valid data) expressed their dissatisfaction.

\section{Results of Polymerase Chain Reaction (PCR) (detection of viral infection)/Microarray analysis (detection of bacterial DNA)}

One hundred and nineteen swab samples were available for analysis. Virus DNA was detected in 61 of the 119 samples (51.3\%). The

\begin{tabular}{|c|c|c|c|c|c|}
\hline & \multirow[t]{2}{*}{ Visit } & \multirow[t]{2}{*}{$\mathrm{n}$} & \multirow{2}{*}{$\begin{array}{l}\text { Total score } \\
\text { Mean SD }\end{array}$} & \multicolumn{2}{|c|}{$\begin{array}{c}\text { Change versus } \\
\text { baseline }\end{array}$} \\
\hline & & & & Mean SD & $\mathbf{p}$ \\
\hline \multirow{3}{*}{$\begin{array}{l}\text { Common } \\
\text { cold } \\
\text { symptoms }\end{array}$} & Baseline & 120 & $10.8 \pm 3.6$ & & \\
\hline & Day 5 & 117 & $5.1 \pm 3.4$ & $-5.6 \pm 3.8$ & $<0.001$ \\
\hline & $\begin{array}{l}\text { Day } 10 \text { (treatment } \\
\text { end) }\end{array}$ & 117 & $2.2 \pm 2.5$ & $-8.6 \pm 4.0$ & $<0.001$ \\
\hline \multirow{3}{*}{$\begin{array}{c}\text { Other } \\
\text { ARP- } \\
\text { associated } \\
\text { complaints }\end{array}$} & Baseline & 120 & $3.4 \pm 2.7$ & & \\
\hline & Day 5 & 117 & $1.3 \pm 1.9$ & $-2.1 \pm 2.4$ & $<0.001$ \\
\hline & $\begin{array}{l}\text { Day } 10 \text { (treatment } \\
\text { end) }\end{array}$ & 117 & $0.5 \pm 1.3$ & $-2.8 \pm 2.6$ & $<0.001$ \\
\hline
\end{tabular}

Investigators' ratings; mean $\pm \mathrm{SD}$ and Wilcoxon test for change versus baseline; FAS

Table 2: Total scores of common cold symptoms and other ARP-associated symptoms

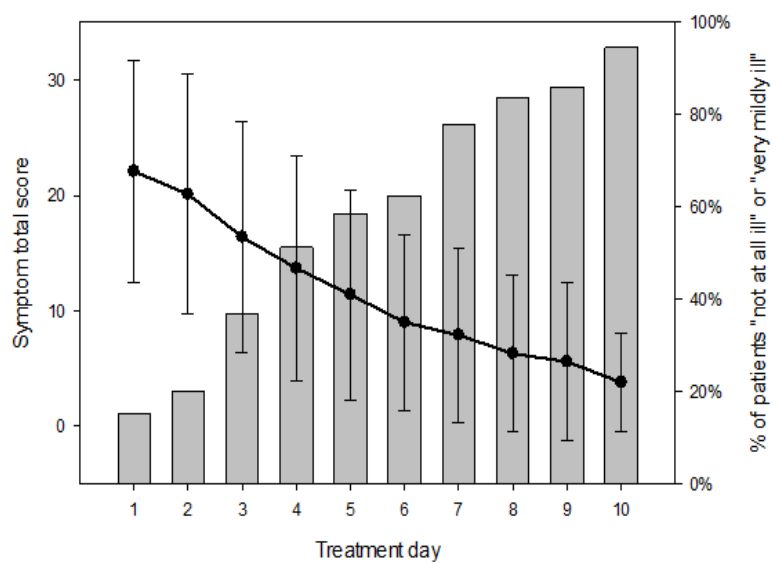

Figure 1: Patient diary ratings of ARP-associated complaints (mean $\pm S D$ ) and $\%$ of patients feeling not at all ill or very mildly ill $(n=119 \ldots 92)$

most frequently detected viruses were enterovirus/rhinovirus (29\% of the samples).

BacterialDNA wasidentified in 118 samples (99.2\%). Staphylococcus epidermidis was the organism identified most frequently.

\section{Tolerability and safety}

During treatment with EPs 7630, 15 of 120 subjects exposed (12.5\%) reported 18 AEs. Ten events observed in 9 patients (7.5\%) were assessed to be potentially treatment-related. Considering a cumulative exposure of 1,064 treatment days, these numbers correspond to an over-all incidence density of 0.017 AEs per day of exposure or to $1 \mathrm{AE}$ in 71 days of treatment for all events, and to 0.009 events per day of exposure or 1 event in 106 treatment days for potentially related events. None of the events were serious.

Table 4 provides an overview of all adverse events according to MedDRA Preferred Terms. Among the 10 events for which a causal relationship with the investigational treatment could not be excluded, only an allergic dermatitis was assessed to be possibly related whereas all others were considered to be improbably related.

The MedDRA System Organ Class with the largest number of patients affected by an $\mathrm{AE}$ was gastrointestinal disorders (6, 5.0\%, 95\% CI: $2.3-10.5 \%$ ) followed by nervous system disorders and respiratory, thoracic and mediastinal disorders (both 3, 2.5\%, 95\% CI: 0.9-7.1\%). 
Citation: Keck T, Strobl A, Stracke B (2015) Tolerability and Treatment Effects of Pelargonium sidoides Preparation EPs 7630 in Adults Suffering from Acute Rhinopharyngitis - A Prospective, Open-Label Trial. Altern Integ Med 4: 204. doi:10.4172/2327-5162.1000204

\begin{tabular}{|c|c|c|c|}
\hline & & $\begin{array}{l}\text { Investigators' } \\
\text { rating }\end{array}$ & Patients' rating \\
\hline \multirow{6}{*}{ IMOS } & Patients with valid data & $n=117$ & $n=82$ \\
\hline & Complete recovery & $49(41.9 \%)$ & $36(43.9 \%)$ \\
\hline & Major improvement & $49(41.9 \%)$ & $32(39.0 \%)$ \\
\hline & Slight to moderate improvement & $16(13.7 \%)$ & $9(11.0 \%)$ \\
\hline & No change & $3(2.6 \%)$ & $5(6.1 \%)$ \\
\hline & Deterioration & $0(0.0 \%)$ & $0(0.0 \%)$ \\
\hline \multirow{6}{*}{ IMPSS } & Patients with valid data & & $n=101$ \\
\hline & Very satisfied & & $38(37.6 \%)$ \\
\hline & Satisfied & & $37(36.6 \%)$ \\
\hline & Neutral & & $24(23.8 \%)$ \\
\hline & Dissatisfied & & $1(1.0 \%)$ \\
\hline & Very dissatisfied & & $1(1.0 \%)$ \\
\hline
\end{tabular}

Table 3: Integrative Medicine Outcome Scale (IMOS) and Integrative Medicine Patient Satisfaction Scale (IMPSS) - patients' and investigators' ratings at end of treatment/day 10 (last observation carried forward).

\begin{tabular}{|c|c|c|c|}
\hline System Organ Class & Preferred Term & All events & $\begin{array}{l}\text { Events } \\
\text { for which } \\
\text { a causal } \\
\text { relationship } \\
\text { was not } \\
\text { entirely } \\
\text { excluded" }\end{array}$ \\
\hline \multirow{5}{*}{$\begin{array}{l}\text { Gastrointestinal } \\
\text { disorders }\end{array}$} & Abdominal pain & $1(0.8 \%)$ & $1(0.8 \%)$ \\
\hline & Abdominal pain upper & $1(0.8 \%)$ & $1(0.8 \%)$ \\
\hline & Diarrhoea & $1(0.8 \%)$ & $1(0.8 \%)$ \\
\hline & Flatulence & $2(1.7 \%)$ & $2(1.7 \%)$ \\
\hline & Toothache & $1(0.8 \%)$ & - \\
\hline $\begin{array}{l}\text { Infections and } \\
\text { infestations }\end{array}$ & Urinary tract infection & $1(0.8 \%)$ & - \\
\hline Investigations & $\begin{array}{l}\text { Activated partial } \\
\text { thromboplastin time } \\
\text { prolonged }\end{array}$ & $1(0.8 \%)$ & $1(0.8 \%)$ \\
\hline $\begin{array}{l}\text { Musculoskeletal and } \\
\text { connective tissue } \\
\text { disorders }\end{array}$ & Back pain & $1(0.8 \%)$ & - \\
\hline \multirow{2}{*}{$\begin{array}{l}\text { Nervous system } \\
\text { disorders }\end{array}$} & Headache & $1(0.8 \%)$ & - \\
\hline & Migraine & $2(1.7 \%)$ & $2(1.7 \%)$ \\
\hline Psychiatric disorders & Sleep disorder & $1(0.8 \%)$ & - \\
\hline \multirow{3}{*}{$\begin{array}{l}\text { Respiratory, thoracic } \\
\text { and mediastinal } \\
\text { disorders }\end{array}$} & Dysphonia & $1(0.8 \%)$ & - \\
\hline & Oropharyngeal pain & $1(0.8 \%)$ & - \\
\hline & Sneezing & $1(0.8 \%)$ & - \\
\hline \multirow{2}{*}{$\begin{array}{l}\text { Skin and } \\
\text { subcutaneous tissue } \\
\text { disorders }\end{array}$} & Dermatitis allergic & $1(0.8 \%)$ & $1(0.8 \%)$ \\
\hline & Rash & $1(0.8 \%)$ & $1(0.8 \%)$ \\
\hline Any adverse events & & $15(12.5 \%)$ & $9(7.5 \%)$ \\
\hline
\end{tabular}

\# Causal drug relationship: 'probable', 'possible', or 'unlikely'

Table 4: Patients with adverse events (MedDRA System Organ Classes and Preferred Terms), by causal relationship $(n=120)$

Except for one case of prolonged activated partial thromboplastin time (reported as an $\mathrm{AE}$ with unlikely causal relationship to the investigational treatment), the safety laboratory measures did not

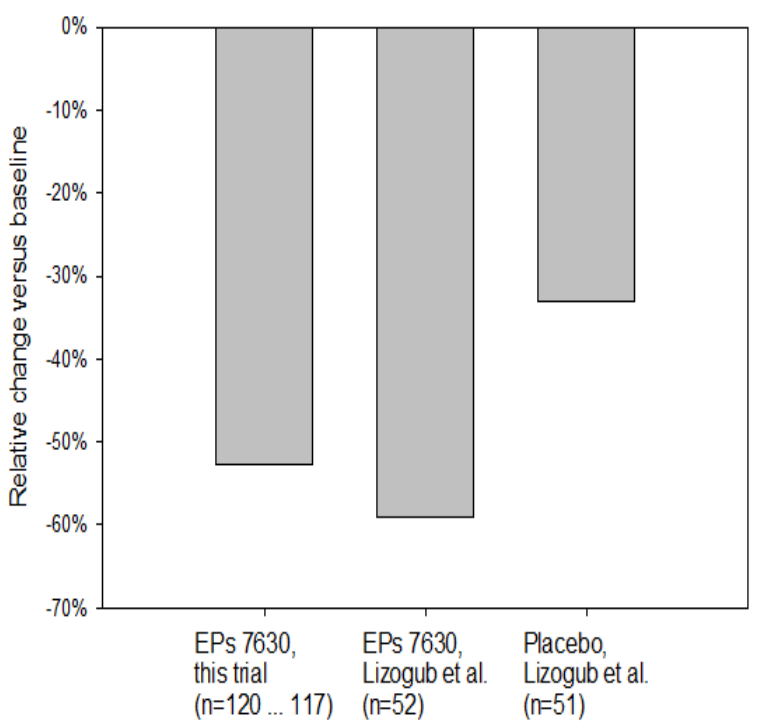

Figure 2: Relative change of ARP symptom score between baseline and treatment day 5 in this trial and in Lizogub et al. [36] (full analysis set; relative mean value difference).

indicate any signs of intolerance, neither on a casuistic basis, nor with respect to a possible shift in the mean value.

\section{Discussion}

Recent reviews taking into account practically all available clinical trials and post-marketing surveillance studies with Pelargonium sidoides extract EPs 7630 published until early 2013 agree that a slight increase in the risk of AEs over the placebo level has to be expected, mainly due to somewhat higher rates of gastrointestinal complaints and hypersensitivity reactions, but that potentially attributable events were always non-serious, non-severe, and transient, not causing an increase in treatment-related withdrawals $[28,29]$.

The safety and tolerability of EPs 7630 were reviewed by Matthys et al. [29] based on data from 29 clinical trials and post-marketing surveillance studies involving more than 10,000 adults and children with respiratory tract infections. Their analyses focused on adverse reactions which, according to the Summary of Product Characteristics (SmPC) of the marketed product, may occur in at least 1 patient out of 10,000 exposed. Among the 5 system groups concerned, gastrointestinal complaints showed a risk difference of $+1.86 \%$ under EPs 7630 as compared to placebo and epistaxis showed a difference of $+0.54 \%$. The remaining system groups (hypersensitivity reactions, gingival bleeding, hepatic enzymes) were associated with risk differences $<0.5 \%$ (data apply to events for which a causal relationship was not entirely excluded). Of note, patients exposed to EPs 7630 did not exhibit an increased risk of elevated liver enzyme or bilirubin values. In placebocontrolled clinical trials, Matthys et al. [29] reported highly variable rates of AEs (any causal relationship) ranging from $1.4 \%$ to $51.5 \%$ in patients treated with EPs 7630 compared to $0.0 \%$ to $39.6 \%$ for placebo. Higher AE rates were predominantly observed in 'smaller' trials with fewer than 100 patients in each treatment group, whereas 'larger' trials reported rates below $20 \%$ on both groups.

With an over-all AE rate of $12.5 \%$ for EPs 7630 , the data from this 
trial are consistent with the review findings and do not indicate an under-reporting of AEs that is not uncommon in open-label trials or observational studies (e.g [35]). It is also worth mentioning that 5 of the 10 potentially attributable events in this trial were gastrointestinal complaints, and 2 were skin reactions, both of which are among the most common types of AEs noted during previous research [28,29]. On the other hand, bleeding complications (e. g., epistaxis, gingival bleeding) or elevated liver enzyme values were not observed during this study.

In a self-limiting condition like ARP, the parameter of clinical interest is not simply improvement compared to baseline, but improvement over the natural course of the disease. As an open-label trial without a control group, this trial was not designed to demonstrate treatment efficacy. It is therefore interesting to note that the extent of symptom relief in our study participants was comparable to that observed in a double-blind, randomized, trial performed by Lizogub et al. [36] in ARP, in which EPs 7630 was significantly superior to placebo. The authors' main outcome measure for efficacy was based on the change of a cold intensity score between baseline and treatment day 5 . The score assessed the same 10 symptoms included in the CCS, albeit on a 5-point verbal rating scale instead of the 4-point scale used in our trial so that the absolute values cannot be compared directly.

Figure 2 shows that the ARP symptom score in Lizogub et al. [36] decreased by $59.0 \%$ and by $33.1 \%$ for EPs 7630 and placebo, respectively, after 5 days of randomized treatment, compared to a $52.8 \%$ decrease observed in the present, uncontrolled trial. We interpret this as evidence that the recovery of symptoms observed in our trial was not caused by the natural course of ARP alone, all the more since recent research indicates that placebo effects in ARP are limited and nuanced [37].

Another indicator for a beneficial effect of EPs 7630 is the observation of an association between recovery and the initiation of treatment relative to the onset of ARP. Our trial shows evidence that treatment with EPs 7630 may be most efficacious when initiated within the first $24 \mathrm{~h}$ after the first symptoms are noted, although the interpretation is limited by the fact that this result was observed in an exploratory post-hoc analysis.

After demonstrating the efficacy of a medicinal product in randomized placebo-controlled trials performed in rigorously standardized settings, interventional post-marketing trials in the registered indication represent a logical next step in order to gain primarily further safety information in a clinical real-life setting [30]. On the other hand, an uncontrolled trial may tend to provide an overly optimistic estimate of the efficacy of an intervention because it does not permit a separation of the pharmacological effect of a product from its placebo effect. Uncontrolled open-label studies are subject to several limitations (e.g. $[35,38]$ ), and therefore should be interpreted carefully. However, comparisons of the course of symptom recovery as well as of the rate and type of adverse events observed in this study and in controlled clinical trials with EPs 7630 in acute respiratory tract infections show that the results were in a similar range, making bias as a consequence of the uncontrolled design unlikely.

Recent studies have shown that a complex bacterial milieu exists within the human upper respiratory tract - including that of healthy individuals -, the predominant species of which are staphylococcus spp., which do usually not cause any clinical manifestations $[39,40]$. This is consistent with the results of the viral and bacterial analysis of the swab obtained at baseline of our trial, which showed that about half of the samples confirmed a viral infection, whereas all samples except one exhibited proof of bacterial DNA. We interpret the presence of bacterial DNA to be mainly related to the bacterial milieu found in ill and healthy individuals alike, rather than to the specific symptoms of acute rhinopharyngitis. Moreover, although ARP is considered to be almost exclusively a viral disease (e.g [41]), viral detection rates commonly range between about $43 \%$ and $63 \%$ [42,43]. The results of the viral analysis may therefore be attributable to a lack of sensitivity of the assay.

In conclusion, the study confirms the excellent tolerability of EPs 7630 during 10 days' treatment of adult patients suffering from ARP. Potentially attributable AEs were mainly limited to gastrointestinal complaints and skin reactions, which are a part of the known spectrum of adverse effects of the drug. The majority of study participants showed a favorable course of recovery from ARP which is unlikely to be explained by the natural course of the disease alone.

\section{Acknowledgments}

Medical writing services were provided by Dr. Andreas Völp, Psy Consult Scientific Services, Frankfurt, Germany. The study as well as medical writing services were funded by Dr. Willmar Schwabe GmbH \& Co. KG, Karlsruhe, Germany.

TK and AS have received honoraria from Dr. Willmar Schwabe $\mathrm{GmbH} \& \mathrm{Co}$. KG, Karlsruhe, Germany; BS is an employee of Dr. Willmar Schwabe GmbH \& Co. KG, Karlsruhe, Germany.

\section{References}

1. Simasek M, Blandino DA (2007) Treatment of the common cold. Am Fam Physician 75: 515-520.

2. Arroll B (2011) Common cold. Clin Evid 03: 1510.

3. Bertino JS (2002) Cost burden of viral respiratory infections: issues for formulary decision makers. Am J Med 112 Suppl 6A: 42S-49S.

4. Birnbaum HG, Morley M, Greenberg PE, Colice GL (2002) Economic burden of respiratory infections in an employed population. Chest 122: 603-611.

5. Niroumand M, Grossman RF (1998) Airway infection. Infect Dis Clin North Am 12: $671-688$

6. Dreschers S, Franz P, Dumitru CA, Wilker B, Jahnke K, et al. (2007) Infections with human rhinovirus induce the formation of distinct functional membrane domains. Cell Physiol Biochem 20: 241-254.

7. van Kempen M, Bachert C, Van Cauwenberge P (1999) An update on the pathophysiology of rhinovirus upper respiratory tract infections. Rhinology 37: 97-103.

8. Herendeen NE, Szilagy PG (2000) Infections of the upper respiratory tract. In: Behrman RE, Kliegman RM, Jenson HB (eds) Nelson Textbook of pediatrics. $\left(16^{\text {th }}\right.$ edn) W. B. Saunders, Philadelphia 1261-1266

9. Heikkinen T, Jarvinen A (2003) The common cold. Lancet 361: 51-59.

10. Pratter MR (2006) Cough and the common cold: ACCP evidence-based clinical practice guidelines. Chest 129: 72S-74S.

11. Curley FJ, Irwin RS, Pratter MR, Stivers DH, Doern GV, et al. (1988) Cough and the common cold. Am Rev Respir Dis 138: 305-311.

12. Pitrez PM, Pitrez JL (2003) Acute upper respiratory tract infections: outpatient diagnosis and treatment [in Portugese]. J Pediatr (Rio J) 79 Suppl 1: S77-86.

13. Lorber B (1996) The common cold. J Gen Intern Med 11: 229-236.

14. Moyo M, Van Staden J (2014) Medicinal properties and conservation of Pelargonium sidoides DC. J Ethnopharmacol 152: 243-255

15. Kayser O, Kolodziej H, Kiderlen AF (2001) Immunomodulatory principles of Pelargonium sidoides. Phytother Res 15: 122-126.

16. Kolodziej H (2007) Fascinating metabolic pools of Pelargonium sidoides and 
Citation: Keck T, Strobl A, Stracke B (2015) Tolerability and Treatment Effects of Pelargonium sidoides Preparation EPs 7630 in Adults Suffering from Acute Rhinopharyngitis - A Prospective, Open-Label Trial. Altern Integ Med 4: 204. doi:10.4172/2327-5162.1000204

Pelargonium reniforme, traditional and phytomedicinal sources of the herbal medicine Umckaloabo®. Phytomedicine 14 Suppl 6: 9-17.

17. Kolodziej H, Kayser O, Radtke OA, Kiderlen AF, Koch E (2003) Pharmacological profile of extracts of Pelargonium sidoides and their constituents. Phytomedicine 10 Suppl 4: 18-24.

18. Kolodziej $\mathrm{H}$, Kiderlen $\mathrm{AF}$ (2007) In vitro evaluation of antibacterial and immunomodulatory activities of Pelargonium reniforme, Pelargonium sidoides and the related herbal drug preparation EPs $₫ 7630$. Phytomedicine 14 Suppl 6: 18-26.

19. Conrad A, Hansmann C, Engels I, Daschner FD, Frank U (2007) Extract of Pelargonium sidoides (EPS $\left.{ }^{\circledR} 7630\right)$ improves phagocytosis, oxidative burst, and intracellular killing of human peripheral blood phagocytes in vitro. Phytomedicine 14 Suppl 6: 46-51.

20. Conrad A, Jung I, Tioua D, Lallemand D, Carrapatoso F, et al. (2007) Extract of Pelargonium sidoides (EPs $® 7630)$ inhibits the interactions of group A-streptococci and host epithelia in vitro. Phytomedicine 14 Suppl 6: 52-59.

21. Rezaizadehnajafi L, Wink M (2014) EPs $7630 ®$ from Pelargonium sidoides increases stress resistance in Caenorhabditis elegans probably via the DAF16/FOXO pathway. Phytomedicine 21: 547-550.

22. Helfer M, Koppensteiner H, Schneider M, Rebensburg S, Forcisi S, et al (2014) The Root Extract of the Medicinal Plant Pelargonium sidoides Is a Potent HIV-1 Attachment Inhibitor. PloS one 9: e87487.

23. Michaelis M, Doerr HW, Cinatl J, Jr. (2011) Investigation of the influence of $E P s \circledR 7630$, a herbal drug preparation from Pelargonium sidoides, on replication of a broad panel of respiratory viruses. Phytomedicine 18: 384 386.

24. Theisen LL, Muller CP (2012) EPs $₫ 7630$ (Umckaloabo®), an extract from Pelargonium sidoides roots, exerts anti-influenza virus activity in vitro and in vivo. Antiviral Res 94: 147-156.

25. Agbabiaka TB, Guo R, Ernst E (2008) Pelargonium sidoides for acute bronchitis: a systematic review and meta-analysis. Phytomedicine 15: 378385.

26. Agbabiaka TB, Guo R, Ernst E (2009) Erratum to "Pelargonium sidoides for acute bronchitis: A systematic review and meta-analysis" [Phytomedicine 15 (2008) 378-385]. Phytomedicine 16: 798-799.

27. Matthys H, Malek FA, Kamin W (2014) EPs® 7630 in Acute Respiratory Trac Infections - a Systematic Review and Meta-Analysis of Randomised Clinical Trials. Forsch Komplementärmed 21: 57-58.

28. Timmer A, Gunther J, Motschall E, Rucker G, Antes G, et al. (2013) Pelargonium sidoides extract for treating acute respiratory tract infections. Cochrane Database Syst Rev 10: Cd006323.

29. Matthys H, Köhler S, Kamin W (2013) Safety and tolerability of EPs 7630 in clinical trials. Adv Pharmacoepidemiol Drug Saf 2: 142

30. Ray WA, Stein CM (2006) Reform of drug regulation--beyond an independent drug-safety board. N Engl J Med 354: 194-201.

31. Jackson GG, Dowling HF, Spiesman IG, Boand AV (1958) Transmission of the common cold to volunteers under controlled conditions. I. The common cold as a clinical entity. AMA Arch Intern Med 101: 267-278.

32. Mossad SB, Macknin ML, Medendorp SV, Mason P (1996) Zinc gluconate lozenges for treating the common cold. A randomized, double-blind, placebocontrolled study. Ann Intern Med 125: 81-88.

33. Prasad AS, Fitzgerald JT, Bao B, Beck FW, Chandrasekar PH (2000) Duration of symptoms and plasma cytokine levels in patients with the common cold treated with zinc acetate. A randomized, double-blind, placebo-controlled trial. Ann Intern Med 133: 245-252.

34. Steinsbekk A, The Data Collection Group (1999) Data Collection in Homeopathic Practice. A Proposal for an International Standard, European Committee for Homeopathy.

35. Hakobyan L, Haaijer-Ruskamp FM, de Zeeuw D, Dobre D, Denig P (2011) A review of methods used in assessing non-serious adverse drug events in observational studies among type 2 diabetes mellitus patients. Health and quality of life outcomes 9: 83 .

36. Lizogub VG, Riley DS, Heger M (2007) Efficacy of a pelargonium sidoides preparation in patients with the common cold: a randomized, double blind placebo-controlled clinical trial. Explore (NY) 3: 573-584

37. Barrett B, Brown R, Rakel D, Rabago D, Marchand L, et al. (2011) Placebo effects and the common cold: a randomized controlled trial. Annals of family medicine 9: 312-322

38. Lopez-Gonzalez E, Herdeiro MT, Figueiras A (2009) Determinants of underreporting of adverse drug reactions: a systematic review. Drug Saf 32: 19-31.

39. Ramakrishnan VR, Feazel LM, Gitomer SA, Ir D, Robertson CE, et al. (2013) The microbiome of the middle meatus in healthy adults. PloS one 8: e85507.

40. Wos-Oxley ML, Plumeier I, von Eiff C, Taudien S, Platzer M, et al. (2010) A poke into the diversity and associations within human anterior nare microbial communities. The ISME journal 4: 839-851.

41. Mäkelä MJ, Puhakka T, Ruuskanen O, Leinonen M, Saikku P, et al. (1998) Viruses and bacteria in the etiology of the common cold. J Clin Microbiol 36: 539-542.

42. Brittain-Long R, Westin J, Olofsson S, Lindh M, Andersson LM (2010) Prospective evaluation of a novel multiplex real-time PCR assay for detection of fifteen respiratory pathogens-duration of symptoms significantly affects detection rate. J Clin Virol 47: 263-267.

43. Lam WY, Yeung AC, Tang JW, Ip M, Chan EW, et al. (2007) Rapid multiplex nested PCR for detection of respiratory viruses. J Clin Microbiol 45: 3631-3640. 